\title{
El Ciclo Hidrosocial. Una propuesta didáctica desde la historia, la geografía, las ciencias sociales y la educación para la ciudadanía
}

Inmaculada Simón Ruiz y Brandon Aravena Rodríguez. Santiago: Universidad Autónoma de Chile, 2020. 114 páginas.

Carolina Valenzuela Matus*

La reciente propagación del covid-19, de la que hemos sido testigos durante 2020, ha puesto una vez más en evidencia la fragilidad de las relaciones entre el hombre y la naturaleza. Desde hace décadas, la búsqueda del equilibrio con el medio natural parece más un ideal que un hecho concreto y requiere, hoy más que nunca, el cumplimiento de metas y objetivos claros para propiciar un desarrollo sostenible que asegure la vida para las próximas generaciones. Uno de los objetivos más importantes planteados por la ONU en esta materia es garantizar la disponibilidad de agua y su gestión sostenible, y el saneamiento para todos, objetivo que cobra cada vez mayor relevancia en el contexto de la pandemia actual para la lucha contra la propagación de enfermedades infecciosas.

En este sentido, el libro El Ciclo Hidrosocial. Una propuesta didáctica desde la historia, la geografía, las ciencias sociales y la educación para la ciudadanía es una contribución significativa en la visualización de la importancia y el cuidado de los recursos hídricos. El libro va dirigido a un público no especializado y orientado especialmente hacia jóvenes en etapa escolar, combinando, de forma novedosa, la di-

* Chilena. Doctora en Estudios del Mundo Antiguo, Universidad Autónoma de Chile. E-mail: carolina.valenzuela01@uautonoma.cl 
vulgación de un conocimiento académico acerca del tema con la necesidad de propuestas pedagógicas didácticas concretas para aplicar en el aula. A través de sus páginas se plantea claramente que, si se mira el ciclo hidrosocial desde la demanda y no desde la oferta, la cantidad y la calidad del agua disponible para el consumo humano no es, de manera alguna, inagotable.

El primer capítulo está dedicado al agua en la historia de Chile y de la humanidad, desde el periodo prehispánico hasta la revolución industrial. A lo largo de este se explica cómo ha cambiado la relación del ser humano con el agua a través de la historia, destacando dos hitos importantes - la revolución agrícola y la revolución industrial- para describir la evolución de la oferta y la demanda de recursos naturales en general, y del agua en particular.

El segundo capítulo trata sobre el agua en la geografía chilena y cómo las características geográficas (humanas y físicas) del país influyen en la cantidad y la calidad de las aguas disponibles. Demuestra que, hasta el momento, la demanda de agua no ha estado relacionada con la oferta sino con las necesidades productivas y estratégicas (urbanismo, represas, embalses, desviación de cursos de agua), poniendo en riesgo la misma continuidad del sistema. Destaca también la importancia de los glaciares a nivel global, como grandes reservorios de agua, poniendo atención en los riesgos que genera su destrucción.

El capítulo tercero versa sobre los cambios en los usos del suelo y del agua, las modificaciones en el clima y sus consecuencias en el ciclo hidrológico. Estos usos generan transformaciones en la cantidad y la calidad del agua. El uso de aguas por las hidroeléctricas y también por las actividades extractivas, como la minería, generan una intervención importante sobre el curso de los ríos. Otro gran impacto está dado por la agricultura de riego, que demanda una alarmante cantidad de agua.

El cuarto capítulo se refiere al esquema hidrosocial y las consecuencias de la intervención humana en el ciclo del agua. Es destacable la crítica al esquema clásico del ciclo del agua, que no toma en cuenta la intervención humana ni la diversidad climática, o la existencia de inundaciones o aluviones, elementos especialmente relevantes a tener en cuenta para comprender la situación de Chile, caracterizada por su heterogeneidad climática. Además, se señala que la intervención so- 
cial en el ciclo del agua puede tener consecuencias tan negativas como las inundaciones, las que generalmente se producen por la pérdida de la memoria histórica (la historia permitiría identificar el curso original de un río, por ejemplo, antes de ser ocupado por viviendas) y la falta de planificación en el crecimiento de las ciudades. Resulta también importante incluir, en el diagrama del ciclo, la contaminación ambiental que afecta en la drástica disminución de las precipitaciones.

El capítulo quinto aborda el tema de la nueva cultura del agua planteando tres preguntas en una: ¿qué podemos hacer, qué estamos haciendo y por qué debemos actuar? Hace un llamado a los ciudadanos a ser responsables con el cuidado del agua y a cautelar que los organismos responsables de su gestión también lo hagan. Asimismo, invita a tomar medidas individualmente, destinadas a hacer un consumo responsable no solo del agua para el aseo y el consumo cotidiano, sino también de la huella hídrica de los productos y servicios que consumimos diariamente. No obstante, esto debe ir acompañando de la acción de las autoridades, quienes deben cautelar el acceso al agua para el consumo humano privilegiándolo frente a otros usos, y que se cuiden las fuentes de abastecimiento para asegurar su permanencia en el tiempo y su calidad.

Cada uno de los cinco capítulos va acompañado por una sección con orientaciones didácticas para implementar estos contenidos en las aulas, indicando nivel, asignatura a la que aplica (Ciencias Naturales o Historia y Geografía), objetivos de aprendizaje y actividades y productos (elaboración de mapas, búsquedas bibliográficas, lecturas, síntesis, debates). La inclusión de estas estrategias didácticas, además de ser una novedad, contribuye a concretar el proceso de enseñanzaaprendizaje sobre el ciclo hidrosocial. Por tanto, la historia y la didáctica ponen de manifiesto que la única forma de combatir la crisis del agua es el conocimiento y, por tanto, es necesario informarse, estudiar e indagar sobre el tema. Estamos así ante una propuesta innovadora, que reflexiona sobre la relación del ser humano con el ciclo hídrico en pos de la sostenibilidad del agua como recurso en el espacio y tiempo, y hace un importante llamado a la responsabilidad ciudadana en el cuidado medioambiental. 